\title{
The effects of electroconvulsive shock and sound-induced seizure on the retention of a passive avoidance response
}

\author{
HOWARD M. REID \\ State University of New York, College at Buffalo, Buffalo, New York
}

\begin{abstract}
SJL/J mice underwent one-trial passive avoidance training, followed immediately by either electroconvulsive shock (ES) or sound-induced seizure. Testing of the passive avoidance response occurred $72 \mathrm{~h}$ later. It was found that an ES-induced seizure, but not a sound-induced seizure, caused amnesia for the passive avoidance learning.
\end{abstract}

Generalized convulsions resulting from intense auditory stimulation have been noted in a variety of rodent species. These sound-induced or audiogenic seizures are an extensively studied model of the human reflex epilepsies, and, as might be expected, much of the research emphasis has been upon elucidating the conditions that lead to susceptibility. Among the additional topics examined has been the effect of sound-induced seizure upon other behaviors, and, not surprisingly, a number of these studies have investigated whether audiogenic seizure affects memory. In an early study, Shaw, Utecht, and Fullager (1953) concluded that sound-induced seizure did not impair the memory of maze learning in rats. The most recent studies, however, have concluded that audiogenic seizure does induce amnesia (Essman, 1965; Essman \& Hamburgh, 1962).

In the studies that have found an effect upon memory, the audiogenic seizures were elicited following the learning of a water-maze escape response. In the Essman and Hamburgh (1962) paper, it was reported that this pairing increased subsequent latencies to escape if the audiogenic seizure occurred within 2 min of the completion of the water-maze task but not if the seizure was delayed for $1 \mathrm{~h}$. In the Essman (1965) study, a shift to an alternative escape response occurred following the audiogenic seizure. In both cases, the behavioral change was interpreted as indicating that an audiogenic seizure had induced at least partial amnesia of the escape response. It is possible, however, that in both cases the seizure acted as a punisher for the preceding behavior. If so, a subsequent increase in response latency or shift in response preference would not indicate that the seizure had induced amnesia. This difficulty of interpretation could be overcome by using a passive avoidance rather than an escape response. In a passive avoidance situation, engaging in a specified behavior leads to the presentation of a disagree-

This work was supported by Research Grant BMS 15966 from the National Science Foundation to Robert $L$. Collins. The author's mail ing address is Department of Psychology, State University College at Buffalo, Buffalo, NY 14222. able stimulus, such as footshock. As long as the subject refrains from engaging in the specified behavior, the disagreeable stimulus is not presented. If the stimulus is sufficiently aversive, one exposure to it is followed by a decrease in the probability of the subject's engaging in the antidecent behavior. On the other hand, if the event causes amnesia, no such decrease would be expected. This differentiation between amnesic and aversive properties of a stimulus is not possible in the escape tasks employed by Essman (1965; Essman \& Hamburgh, 1962). In the present study, therefore, a passive avoidance task was utilized to test whether audiogenic seizure would induce amnesia for a passive avoidance response in a manner similar to that found with electroconvulsive shock (ES).

\section{METHOD}

\section{Subjects}

One hundred and eighty-five $\mathrm{SJL} / \mathrm{J}$ mice were included in the study. These mice were obtained from the production facility of the Jackson Laboratory at $16 \pm 3$ days of age. Though initially resistant to audiogenic seizure, this strain of mice has been found to become susceptible following an initial exposure to a loud sound (sensitization) (Fuller \& Collins, 1968). Subjects had access to food and water ad lib, and were housed in groups of 4 or 5 .

\section{Apparatus}

The apparatus consisted of a Grason-Stadler Model E1064GS shock generator, a Hewlett-Packard Electroanesthesia Model 3380B ES inducer, an audiogenic seizure chamber, and a passive avoidance shock box.

The shock box was a rectangular, clear Plexiglas chamber that measured $27 \times 10.5 \times 16.5 \mathrm{~cm}$. It was divided into two compartments, each $13.5 \times 10.5 \times 16.5 \mathrm{~cm}$. One was marked with vertical strips of black 1.9-cm-wide tape spaced $1.6 \mathrm{~cm}$ apart; the other was marked with similarly spaced horizontal strips of tape. The only route between the two compartments was through a $2.5-\mathrm{cm}$ diam hole, $1 \mathrm{~cm}$ above the floor, which the experimenter could close with a Plexiglas plate. Footshock could be delivered through the floor, which was composed of steel rods spaced $.5 \mathrm{~cm}$ apart.

The inside dimensions of the audiogenic seizure chamber were $56.1 \times 43 \times 62 \mathrm{~cm}$. A clear plastic cylinder, measuring $30.5 \mathrm{~cm}$ in diameter and $30 \mathrm{~cm}$ in height, was centered within the audiogenic seizure chamber. A Trine 204A electric bell (measured to have a peak intensity of $102 \mathrm{~dB}$ re: $.0002 \mathrm{dyn} / \mathrm{cm}^{2}$ ) was centered 
Table 1

Design of the Experiment

\begin{tabular}{|c|c|c|}
\hline & $\begin{array}{c}\text { Audiogenic Seizure } \\
\text { Groups }\end{array}$ & $\begin{array}{c}\text { ES } \\
\text { Groups }\end{array}$ \\
\hline $\begin{array}{l}\text { No footshock } \\
\text { No seizure }\end{array}$ & $\begin{array}{c}\text { Learning } \\
\text { control } \\
(\mathrm{FS}-\mathrm{AS}-)\end{array}$ & $\begin{array}{c}\text { Learning } \\
\text { control } \\
(\mathrm{FS}-\mathrm{ES}-)\end{array}$ \\
\hline $\begin{array}{l}\text { Footshock } \\
\text { No seizure }\end{array}$ & $\begin{array}{c}\text { Passive avoidance } \\
\text { learning } \\
(\mathrm{FS}+\mathrm{AS}-\text { ) }\end{array}$ & $\begin{array}{c}\text { Passive avoidance } \\
\text { learning } \\
\text { (FS+ES-) }\end{array}$ \\
\hline $\begin{array}{l}\text { No footshock } \\
\text { Seizure }\end{array}$ & $\begin{array}{c}\text { Seizure } \\
\text { only } \\
(\mathrm{FS}-\mathrm{AS}+)\end{array}$ & $\begin{array}{c}\text { Seizure } \\
\text { only } \\
\text { (FS-ES+) }\end{array}$ \\
\hline $\begin{array}{l}\text { Footshock } \\
\text { Seizure }\end{array}$ & $\begin{array}{c}\text { Passive avoidance } \\
\text { leaming } \\
\text { and seizure } \\
\text { (FS }+\mathrm{AS}+\text { ) }\end{array}$ & $\begin{array}{c}\text { Passive avoidance } \\
\text { learning } \\
\text { and seizure } \\
\text { (FS +ES }+ \text { ) }\end{array}$ \\
\hline
\end{tabular}

Note-Identification of experimental classification: FS = footshock, AS = audiogenic seizure; ES = electroconvulsive shock.

$41 \mathrm{~cm}$ directly over the cylinder when the top of the chamber was closed.

The electroanesthesia inducer provided an electroconvulsive shock with a duration of $1 \mathrm{sec}$ at $8 \mathrm{~mA}$. Eighty percent of this current consisted of a $1000-\mathrm{Hz}$ sine wave; the remaining $20 \%$ was a 100 $\mathrm{Hz}$ sine wave.

\section{Procedure}

The SJL/J mice were sensitized at $17 \pm 3$ days of age by being exposed to the ringing of the bell for $30 \mathrm{sec}$. Three days later, the mice were randomly assigned to one of eight experimental groups, as shown in Table 1. The mice were then placed into one side of the passive avoidance apparatus. The door separating the compartments was opened after $30 \mathrm{sec}$. As soon as the mouse entered the second compartment, the door was closed. Depending upon the experimental classification, mice then received either no footshock or an alternating currect footshock of $1.0 \mathrm{~mA}$ delivered for $0.5 \mathrm{sec}$. Mice belonging to one of the four groups of the audiogenic seizure classification were then placed into the audiogenic seizure chamber, but only mice in two of these groups actually underwent a seizure (Table 1). After removal from the passive avoidance apparatus, mice in each of the four groups of the ES classification had a clip attached to each ear instead of being placed into the audiogenic seizure chamber. As before, only mice in two of these groups underwent a seizure. Since impairment in retention occurs only if there is a short delay between training and the onset of the seizure (e.g., Hine \& Paolino, 1970), any subject with a delay greater than $30 \mathrm{sec}$ was discarded. Furthermore, the subjects in the ES-induced seizure groups were matched with subjects in the audiogenic sei-

Table 2

Mean Latency (in Seconds) for the Test Crossing

\begin{tabular}{lcc}
\hline & $\begin{array}{c}\text { Audiogenic Seizure } \\
\text { Groups }\end{array}$ & $\begin{array}{c}\text { ES } \\
\text { Groups }\end{array}$ \\
\hline $\begin{array}{l}\text { No footshock } \\
\text { No seizure }\end{array}$ & 65.7 & 80.0 \\
$\begin{array}{l}\text { Footshock } \\
\text { No seizure }\end{array}$ & 180.5 & 167.7 \\
$\begin{array}{l}\text { No footshock } \\
\text { Seizure }\end{array}$ & 141.3 & 78.2 \\
$\begin{array}{l}\text { Footshock } \\
\text { Seizure }\end{array}$ & 166.6 & 106.9 \\
\hline
\end{tabular}

zure groups in order to ensure that ES and audiogenic seizures (AS) occur with the same delay after footshock (FS; mean delay = $15.0 \mathrm{sec})$.

Fourteen mice had to be excluded from the study, including 7 for which more than $30 \mathrm{sec}$ elapsed between the time they went through the doorway and the time they underwent a seizure, 3 that did not undergo a scheduled seizure, and 4 that did not go through the doorway within 4.5 min during the training session.

Seventy-two hours later all subjects were tested in the passive avoidance apparatus. As before, the door separating the compartments was opened after $30 \mathrm{sec}$, and each session ended $4.5 \mathrm{~min}$ later, regardless of the animal's behavior. Any subject that had not crossed into the second compartment by this time was given a score of $270 \mathrm{sec}$.

\section{RESULTS}

Data were obtained from 171 subjects. As expected, the subjects that experienced AS exhibited clonic spasms that rarely progressed to a tonic level, whereas the ESinduced seizures characteristically had a tonic-clonic sequence.

No differences were found between the groups in the latency to cross into the second compartment during the training session [mean latency $=67.2 \mathrm{sec} ; F(7,163)=$ $0.28, p>.05]$. However, latencies were found to differ when subjects were tested $72 \mathrm{~h}$ later $[F(7,163)=6.28$, $p<.01$ ] (Table 2). A series of Fisher LSD protected $t$ tests were then utilized to determine which groups differed. Within the overall ES experimental classification, the learning control subjects (FS-ES -) were found to differ from those in the footshock group (FS+ES-) $[t(163)=3.482, p<.01]$ but not from the subjects that received only $\mathrm{ES}(\mathrm{FS}-\mathrm{ES}+)[t(163)=.068, p>.05]$ or ES preceded by footshock (FS $+E S+)[t(163)=1.100$, $p>$.05]. Finally, the subjects that received both footshock and ES (FS +ES +) exhibited significantly shorter latencies than subjects that received only footshock $(\mathrm{FS}+\mathrm{ES}-)[t(163)=2.680, p<.01]$.

Within the overall audiogenic seizure classification, the learning control subjects (FS - AS - ) were found to differ from those in the footshock group (FS + AS -$)[t(163)=$ $4.415, p<.01]$, the seizure group (FS $-\mathrm{AS}+$ ) $[t(163)$ $=2.584, p<.05]$, and the footshock-seizure group $(\mathrm{FS}+\mathrm{AS}+)[t(163)=3.621, p<.01]$. The subjects that received both footshock and an audiogenic seizure $(F S+A S+)$ did not exhibit latencies significantly different from those exhibited by the subjects that received only footshock (FS + AS - ) $[t(163)=.527, p>.05]$.

The only significant differences between the analogous audiogenic seizure and ES groups occurred in subjects that received only a seizure (FS-AS+ and FS-ES+) $[t(163)=2.159, p<.05]$ or footshock and then a seizure $(\mathrm{FS}+\mathrm{AS}+$ and $\mathrm{FS}+\mathrm{ES}+)[t(163)=2.365$, $p<.05]$.

\section{DISCUSSION}

It was predicted that subjects in the ES classification would exhibit behavior similar to that found in other 
studies that had examined the effects of ES-induced seizures on prior learning (e.g., Miller \& Springer, 1973; Riccio \& Richardson, 1984). Specifically, it was expected that subjects assigned to FS-ES-, FS-ES+, and FS + ES + would behave similarly, but that those receiving FS + ES - (footshock but no seizure) would exhibit longer latencies before crossing into the adjacent compartment. The data support these predictions. There is evidence, therefore, that an ES-induced seizure causes amnesia for immediately preceding events under the conditions employed in this study.

It was expected, and found, that the subjects within the audiogenic seizure groups that did not receive a seizure (FS - AS - and FS + AS-) would not differ from similar subjects within the ES classification (FS-ES - and FS +ES -). There was no prediction as to how an audiogenic seizure would affect the memory of previous events. If, however, an audiogenic seizure resulted in amnesia, one would expect to find the same pattern of results as that described for the ES groups. Specifically, one would expect subjects that received FS-AS + or FS + AS + to be similar to subjects in the FS-AS - group but different from those assigned to the FS + AS - condition. If an audiogenic seizure did not result in amnesia, one would predict that subjects in the FS + AS - and FS + AS + conditions would be comparable, whereas those assigned to FS + AS + would have longer latencies than those in the FS - AS - group. In addition, if the seizure was aversive, FS - AS + subjects would be expected to cross with a longer latency than those in the FS-AS - condition. The results are clearcut: $\mathbf{F S}+\mathrm{AS}-$ and $\mathrm{FS}+\mathrm{AS}+$ subjects crossed with similar latencies, whereas those in the FS + AS + condition exhibited longer latencies than those assigned to the FS - AS - group. In addition, FS-AS + subjects took significantly longer to cross than did FS - AS - subjects. It is evident, therefore, that audiogenic seizure, unlike ES-induced seizure, does not result in amnesia of prior learning under the conditions of this study. Instead, the audiogenic seizure appears to be an aversive event.

One explanation for this contrast in effect upon memory could be that the physiological structures affected by audiogenic seizure differ markedly from those involved in an ES-induced seizure. It has been reported, for instance, that audiogenic seizure does not lead to the increased cortical discharge activity that is characteristic of those induced by ES (Wada \& Ikeda, 1969). Instead, animals undergoing an audiogenic seizure exhibit a reduction of cortical activity regardless whether clonic or clonic-tonic behavior patterns are elicited (Maxson \& Cowen, 1976).

Alternatively, the difference found between the effects of ES and audiogenic seizure could be due to the level of seizure exhibited. In the present study, ES almost invariably resulted in a tonic-clonic seizure, whereas audiogenic seizure rarely progressed beyond clonic spasms. Tonic seizures can be induced with sound, but extraordi- nary steps such as immediate resuscitation (reviewed in Collins, 1972) or conducting the test in a high-oxygencontent atmosphere (Willott \& Henry, 1976) must be taken to prevent the subjects from dying.

Previous studies that have examined the effect of audiogenic seizure upon retention have not indicated what proportion of seizures reached a tonic level. However, since no mention was made either of substantial death rates or measures to counter them, it is likely that the seizures were largely limited, as in the present study, to clonic spasms. Accordingly, the different outcomes of this and some of the previous reports (e.g., Essman, 1965; Essman \& Hamburgh, 1962) are not likely to be due to the level of seizure elicited.

Finally, the long latencies exhibited in the passive avoidance test by subjects that had received an audiogenic seizure (FS - AS + and FS + AS +) could be interpreted as being the result of some long-term side effect, such as motor impairment. This is unlikely to be the case, however, since both of the studies by Essman (1965; Essman \& Hamburgh, 1962) included extensive controls to check for such a possibility. No motor impairment was found, even though the testing occurred only $1 \mathrm{~h}$ rather than 3 days, as in the present study, following the inducement of the seizure.

It is not possible, of course, to design a study that can prove that audiogenic seizure is incapable of causing amnesia under any circumstances. Nevertheless, the contrast in the effects of ES and sound-induced seizure when using a passive avoidance task suggests that the previous reports of amnesia with audiogenic seizure were probably the consequence of employing experimental designs that did not control for the aversive properties of this phenomenon.

\section{REFERENCES}

Collins, R. L. (1972). Audiogenic seizures. In D. P. Purpura, J. K. Penry, D. Tower, D. M. Woodbury, \& R. Walker (Eds.), Experimental models of epilepsy: A manual for the laboratory worker (pp. 347372). New York: Raven Press.

Essman, W. N. (1965). Retrograde amnesic effect of audiogenic seizure on the reversal of a maze response. Perceptual \& Motor Skills, 20, 501-504.

Essman, W. B., \& Hamburgh, M. (1962). Retrograde effect of audiogenic seizure upon the retention of a learned response. Experimental Neurology, 6, 245-251.

FulleR, J. L., \& Collins, R. L. (1968). Temporal parameters of sensitization for audiogenic seizures in SJL/J mice. Developmental Psychobiology, 1, 185-188.

Hine, B., \& Paolino, R. M. (1970). Retrograde amnesia: Production of skeletal but not cardiac response gradient by electroconvulsive shock. Science, 169, 1224-1226.

MAXson, S. C., \& CowEN, J. S. (1976). Electroencephalographic correlates of the audiogenic seizure response of inbred mice. Physiology \& Behavior, 16, 623-629.

Miller, R. R., \& Springer, A. D. (1973). Amnesia, consolidation and retrieval. Psychological Review, 80, 69-79.

Riccio, D. C., \& Richardson, R. (1984). The status of memory following experimentally induced amnesias: Gone, but not forgotten. Physiological Psychology, 12, 59-72. 
Shaw, W. A., Utecht, A. J., \& Fullager, E. A. (1953). The effect of auditory stimulation upon the immediate retention of a previously learned maze behavior in the albino rat. Journal of Comparative \& Physiological Psychology, 46, 212-215.

WADA, J., \& IKEDA, H. (1969). Phenomenological and pharmacological identity of audiogenic-sensitive state in animals treated with methionine sulfoximide and in genetically audiogenic-seizure-susceptible animals. Recent Advances in Biological Psychiatry, 9, 131-153.
Willott, J. F., \& Henry, K. R. (1976). Roles of anoxia and noiseinduced hearing loss in the postictal refractory period for audiogenic seizures in mice. Journal of Comparative \& Physiological Psychology, 90, 373-381.

(Manuscript received January 6, 1987; revision accepted for publication June 25,1987 .) 